\title{
DIREITO E DIREITOS HUMANOS: UM DIÁLOGO INTERDISCIPLINAR
}

\author{
Bibiana Graeff ${ }^{1}$ \\ Guilherme Assis de Almeida ${ }^{2}$
}

Nosso objetivo é possibilitar que as pessoas que leiam este artigo possam vislumbrar um pouco do diálogo que empreendemos habitualmente na disciplina que criamos junto ao Programa de Pós-Graduação em Direito do Largo São Francisco, na área de concentração "Direitos Humanos", além de breve uma retrospectiva da consolidação desta área nesta unidade da Universidade de São Paulo. Encaramos esse desafio pois a emergência do campo "Direitos Humanos", intrinsecamente interdisciplinar, na mais tradicional Faculdade de Direito do Brasil, é um desafio constante para toda comunidade acadêmica da USP, vale dizer: corpo docente, estudantes e funcionários.

Com inspiração no modelo do plan francês, ${ }^{3}$ uma das alternativas metodológicas apresentadas e propostas em nossa disciplina conjunta, nosso diálogo será estruturado da seguinte forma. Num primeiro momento, abordaremos a inserção e consolidação do campo dos Direitos Humanos na Pós-Graduação da Faculdade de Direito Largo São Francisco da Universidade de São Paulo (I). Na segunda parte, trataremos mais especificamente da disciplina História dos Direitos Humanos e a Questão do Sujeito (II).

PARTE I - Direitos Humanos na Pós-Graduação da Faculdade de Direito da USP

A pós-graduação em Direito na FDUSP foi estabelecida por meio da portaria GR número 1.211, de 25 de junho de 1970, em plena ditadura militar, tendo a Universidade de São Paulo como reitor o professor Miguel Reale. Atualmente a PósGraduação é organizada em onze áreas de concentração, entre as quais a de Direitos Humanos. A normativa da Comissão de Pós-Graduação da FDUSP assim define área de concentração:

Entende-se por área de concentração cada campo específico do conhecimento que faz parte de um programa de Pós-Graduação, com um elenco variado de disciplinas, dentro da qual deverão desenvolver-se as atividades de

\footnotetext{
Professora adjunta da Escola de Artes, Ciências e Humanidades da Universidade de São Paulo.

2 Professor Associado do Departamento de Filosofia e Teoria Geral do Direito da Faculdade de Direito da Universidade de São Paulo.

3 Para uma visão crítica acerca do plan francês: BARRAUD, B. L'usage du plan en deux parties dans les facultés de droit françaises. RTDCiv: Revue trimestrielle de droit civil, Dalloz, 2015, p. 807-825.
} 
pesquisa para elaboração da dissertação de mestrado ou tese de doutorado. ${ }^{4}$

A área de concentração em Direitos Humanos possui uma linha de pesquisa "Direitos Humanos e Inclusão Social" e cinco projetos acadêmicos de pesquisa. ${ }^{5}$ Direitos Humanos é a mais nova área de concentração, estabelecida, no ano de 2005, e tendo iniciado suas atividades no ano de 2006.

Conjuntamente com o estabelecimento da pós em Direitos Humanos (FDUSP), surgem a pós em Direitos Humanos na Universidade Federal do Pará (UFPA) e na Universidade Federal da Paraíba (UFPB). Importante esclarecer que na UFPA Direitos Humanos é a única área de concentração da pós em Direito da UFPA com 4 linhas de pesquisa e, na UFPB, surge como uma das áreas de concentração do curso de Direito. Esses três Programas de pós-graduação em Direito (PPGD) venceram um Programa de dotação financeira lançado pela Fundação Ford, em junho de 2003, com o apoio da Fundação Carlos Chagas. No âmbito desse esforço da Fundação Ford, para implementação da área de direitos humanos no ensino superior do Brasil surgiu a ANDHEP (Associação Nacional de Direitos Humanos Pesquisa e Pós-Graduaçãoo ${ }^{6}$ que veio a realizar seu primeiro encontro nacional na PUC-RJ (2004).

$\mathrm{O}$ apoio financeiro da Fundação Ford e a supervisão técnica da FCC foram imprescindíveis para a estruturação da área de concentração em direitos humanos da FDUSP. Tal fato é indicativo de como a área de direitos humanos é um fator de abertura da FDUSP a outras instituições e profissionais para além do campo jurídico. Importante deixar registrado o papel do atual presidente da CPG, Fernando Facury Scaff, que, na época das negociações com a CAPES para a implementação da área de direitos humanos na pós-graduação do Brasil, foi um dos responsáveis diretos pela solução inicial que foi encaminhada, vale dizer: direitos humanos como uma área de concentração da pós em Direito. $^{7}$

4 Informação obtida em www.direito.usp.br. Acesso em: 26 jan. 2021.

5 Os projetos acadêmicos são: Democracia, igualdade e combate à discriminação; O direito à educação, à saúde, ao meio ambiente e ao trabalho no combate à exclusão; Direito e exclusão social na história: Aspectos jurídicos e filosóficos; Mecanismos nacionais e internacionais de proteção dos direitos humanos; Direito à diversidade no pensamento político contemporâneo. Reconhecimento, redistribuição, políticas multiculturais. In: http://www.direito.usp.br/cbt/linha_pesquisa/dhu_3.pdf. Acesso em: 4 fev. 2021.

6 Ver: www.andhep.org.br. Acesso em: 4 fev. 2021. Para um histórico detalhado da pós em direitos humanos no Brasil consulte: CARVALHO, Camila Magalhães Campo jurídico e saberes contra hegemônicos: as relações raciais como tema de pesquisa na área de direitos humanos. Doutorado defendido na FDUSP (2018).

7 Atualmente a USP tem duas pós-graduações em Direitos Humanos a da FDUSP e o programa do DIVERSITAS/FFLCH (Núcleo de Estudos das Diversidades, Intolerância e Conflitos) que tem direitos humanos como uma área interdisciplinar 
Agora mostraremos como a área de concentração de Direitos Humanos contribui para a construção de um diálogo interdisciplinar no âmbito da PPGD da FDUSP.

1) Construindo uma experiência interdisciplinar

Para que estudantes ingressem em qualquer outra das dez áreas de concentração do pós da FDUSP, devem ser formados em Direito. A inexigibilidade dessa condição para Direitos Humanos possibilita que pessoas formadas em outras Faculdades estejam presentes na FDUSP, trazendo para reflexão acadêmica da São Francisco um olhar diverso que trabalha com os Direitos Humanos - no primeiro momento - de uma perspectiva não normativa. O primeiro contato de estudantes de outras áreas com a FDUSP é um "estranhamento"... que é quebrado pela discussão em sala de aula e pelo apoio de estudantes da FDUSP no esclarecimento de temas jurídicos. ${ }^{8}$ Importante frisar que as pessoas que orientamos são estimuladas a buscar cursos em outras unidades da USP.

Também a área de concentração em Direitos Humanos acolhe professores de outras unidades da universidade e/ou com outras formações, não exclusivamente jurídicas. Bibiana (coautora desse artigo) é formada na Faculdade de Direito da Universidade Federal do Rio Grande do Sul (UFRGS), tendo realizado seu mestrado em Direito Ambiental na Université Paris I Panthéon-Sorbonne e na Université Paris II Sorbonne-Assas. Fez o seu doutorado com dupla titulação em Direito entre a Universidade Federal do Rio Grande do Sul e a Université Paris I Panthéon-Sorbonne. Após ter trabalhado como professora temporária na Faculdade de Direito da UFRGS em 2008 e 2009, passou em concurso público para assumir, em 2011, a disciplina "Direitos Humanos e Envelhecimento" junto ao Bacharelado em Gerontologia da Escola de Artes, Ciências e Humanidades (EACH) da USP. Em um dos mais jovens campus da USP, inaugurado em 2005 tendo como um dos pilares fundamentais a proposta da interdisciplinaridade, Bibiana assumiu diversas disciplinas colaborando com outros cursos de graduação da Escola, como o curso de Gestão Ambiental e o curso de Gestão de Políticas Públicas, além de buscar integrar produções artísticas teatrais e musicais (áreas nas quais também tem formação e significativa produção) a seus projetos de pesquisa e extensão. Além do PPGD, Bibiana é credenciada junto ao recente Programa de Pós-Graduação em Gerontologia, vinculado à área interdisciplinar da CAPES, onde tem trabalhado junto a colegas da arquitetura, do serviço social, da economia entre outras áreas.

\footnotetext{
8 Um comentário da professora Heloisa Buarque (Antropologia da FFLCH) revelador desse "estranhamento", ao comentar com seus estudantes da FFLCH que tinha uma banca na FDUSP. Os estudantes perguntaram: "Professora a senhora está indo para o castelo de Hogwarts?"; a título de esclarecimento esse é o castelo da série Harry Potter.
} 
Guilherme (o outro coautor desse artigo) é formado na São Francisco e integra o Departamento de Filosofia e Teoria Geral do Direito (DFD), desde 2009. Fez seu pós-doutorado no Núcleo de Estudos da Violência (NEV/USP), núcleo de pesquisa o qual está vinculado até hoje como pesquisador associado, coordenando uma pesquisa intitulada "Teoria integrada dos Direitos Humanos" (2002-2005). Posteriormente fez um segundo pós-doutorado no FRIAS (Freiburg Institut for Advanced Studies) - 2014/2015 sob a supervisão de Hans Joas. Guilherme dá aulas de graduação nos cursos de Ciências Contábeis da FEA/USP e no IRI/USP. Portanto a questão da interdisciplinaridade é uma constante na sua vida como professor, pesquisador e orientador.

Após sua estadia no FRIAS e as conversas com Hans Joas. ${ }^{10}$ Guilherme debruçou-se sobre uma análise histórica dos Direitos Humanos. Nessa perspectiva, um livro referência: "A Sacralidade da Pessoa: uma nova genealogia dos Direitos Humanos". Esse tema foi central na elaboração de sua tese de livre docência publicada em 2018: "Proteção da Pessoa Humana no Direito Internacional: Conflitos Armados, Refugiados e Discriminação Racial".

Bibiana tem se dedicado, nos últimos anos, à questão da pessoa idosa como sujeito de direito ${ }^{11}$ e ao estudo das intersecções entre envelhecimento (pessoal e populacional) e os direitos humanos. De 2015 a 2019, coordenou o projeto de pesquisa "A estratégia do Bairro Amigo do Idoso aplicada aos bairros do Brás e da Mooca: ambiência e a construção do envelhecimento ativo", financiado com auxílio regular da FAPESP. Baseada em método proposto pela Organização Mundial da Saúde, ${ }^{12}$ a pesquisa teve por objetivo a análise das percepções de pessoas idosas e de profissionais residentes ou atuantes nos referidos bairros acerca da ambiência dos mesmos, na perspectiva do envelhecimento ativo e digno. A pesquisa gerou inúmeras reflexões e publicações, a exemplo de uma análise que identificou os temas relacionados à educação continuada ao longo da vida que emergiram das falas de pessoas idosas residentes na Mooca. ${ }^{13}$ Bibiana também vem acompanhando o processo de construção do Direito Internacional da

9 A pesquisa teve como supervisor Paulo Sérgio Pinheiro e como segundo coordenador Andrei Koerner (atual professor de Ciência Política do IFCH/UNICAMP).

10 JOAS, Hans. Sacralidade da Pessoa: uma nova genealogia dos direitos humanos. São Paulo: Editora UNESP 2013

11 Sobre a evolução dos direitos da pessoa idosa no Brasil: GRAEFF, B. Fundamentos e evolução dos direitos da pessoa idosa no Brasil: breve panorama. In: Fabiana Rodrigues Barletta; Vitor Almeida. (Org.). A Tutela Jurídica da Pessoa Idosa. 1. ed., 2020, p. 41-50.

12 ORGANIZAÇÃO MUNDIAL DA SAÚdE. Guia Global: Cidade Amiga do Idoso, 2008; WORLD HEALTH ORGANIZATION. WHO age-friendly cities project methodology: Vancouver Protocol. Geneva: WHO, 2007.

13 GRAEFF, B. BESTETTI, M.-L. T.; DOMINGUES, M. A.; CACHIONI, M. Lifelong Learning: Perceptions Collected through the "Age-friendly Cities" Method in the Neighborhood of Mooca, São Paulo (Brazil). Zeitschrift für Weiterbildungsforschung, v. 42, issue 1, p. 1-28, 2019. 
Pessoa Idosa, em especial junto à Organização das Nações Unidas $(\mathrm{ONU})^{14}$ e ao Sistema Interamericano de Direitos Humanos. ${ }^{15}$

Portanto nossa questão teórica comum era a chamada "especificação do sujeito de direito", ${ }^{16}$ e a proposta do curso "História dos Direitos Humanos e o Processo de Especificação do Sujeito de Direito" foi tratar da emergência da pessoa humana no Direito Internacional - da abolição da tortura e escravidão até a Declaração Universal dos Direitos Humanos - e posteriormente dos diversos sujeitos de direito que foram reconhecidos no âmbito do Direito Internacional dos Direitos Humanos.

\section{2) Exercitando o intercâmbio de conhecimentos entre EACH e FDUSP}

Em um artigo intitulado "Direitos Humanos e modernização do pensamento jurídico" publicado, no ano de 2004, no livro "Retratos do Brasil”, o autor José Reinado de Lima Lopes afirma logo no início de seu texto: “(...) o pensamento jurídico brasileiro está em curso de sofrer certa modernização pelo fato de o tema dos direitos humanos ter sido fixado na pauta das discussões jurídicas". ${ }^{17}$

No artigo em tela, Lima Lopes define modernização em dois sentidos:

É necessário esclarecer o que entendo por modernização, já que se trata de um termo usado, sobretudo nas ciências sociais. Vou usá-lo principalmente como um processo de predomínio das relações abstratas sobre as relações primárias, uma saída da esfera da família para a esfera pública (mercado e política), em outras palavras, à moda weberiana. Modernização também diz respeito, a meu ver, à pluralização das idéias: menos unanimidade e maior necessidade de defender-se contra outras interpretações possíveis da vida jurídica. Nesse segundo sentido, modernização significa também o

14 Em 2012, Bibiana participou, como representante da International Association of Gerontology and Geriatrics, do Brasil, da terceira reunião de grupo criado em 2010 junto à ONU para debater as alternativas internacionais de proteção e fortalecimento dos direitos das pessoas idosas, Third Session of the Openended Working Group on strengthening the protection of the human rights of older persons United Nations: https://social.un.org/ageing-working-group/. Acesso em: 1 fev. 2021.

15 Em 2020, foi defendida pela egressa Maria Emiliana Herrmann, a primeira dissertação de mestrado sob orientação da Profa. Bibiana Graeff no PPGDIR, sendo a mesma dedicada à Convenção Interamericana de Direitos Humanos dos Idosos. Ver também trabalho publicado sobre os avanços socioambientais nessa Convenção: GRAEFF, B. Avanços socioambientais da Convenção Interamericana de Direitos Humanos das Pessoas Idosas. $22^{\circ}$ Congresso Brasileiro de Direito Ambiental. Direito e Sustentabilidade na Era do Antropoceno: Retrocesso Ambiental, Balanço e Perspectivas, 2017, p. 63-85.

16 Ao que parece, o tema "especificação do sujeito de direito" surge, pela primeira vez, no artigo "A Era dos Direitos" (p. 26-32) de Norberto Bobbio, publicado na obra A Era dos Direitos. Bobbio, N. Rio de Janeiro: Campus Elsevier, 2004.

17 LIMA LOPES, J. R. Direitos Humanos e Modernização do Pensamento Jurídico Brasileiro. In REIS, Elisa P. e ZILBERMAN, Regina. Retratos do Brasil. Porto Alegre: EDPUCRS, 2004, p. 85. 
abandono de uma moral tradicional em favor de uma moral crítica. Creio que o tema dos direitos humanos, por ser tão polêmico no Brasil - como em toda parte leva a essa espécie de modernização". $(\ldots)^{18}$

Lima Lopes elenca e analisa três possibilidades para modernização do pensamento jurídico brasileiro propiciadas pela emergência da pauta dos direitos humanos, vale dizer: 1) modernização legislativa; 2) modernização das práticas institucionais; 3 ) modernização da cultura. ${ }^{19}$

Ao tratar da questão dos direitos humanos chega a duas conclusões de nosso interesse. A primeira: "Em resumo quero dizer que a consciência moral da universalidade dos direitos humanos está longe de ser forte entre nós" ${ }^{20} \mathrm{E}$ a segunda, ao tratar da questão da discussão acadêmica, é:

Merece ser mencionado o fato de que o tema dos direitos humanos aparece já em disciplinas específicas em muitos currículos e surgem trabalhos acadêmicos e de doutrina voltados para o assunto. Diversos elementos contribuem para a modernização dos métodos e do conteúdo da discussão acadêmica: a interdisciplinaridade, que obrigou juristas e outros profissionais a dialogarem $[\ldots]$.

Essas duas afirmações continuam válidas, dezessetes anos depois de serem feitas... É um desafio acadêmico e cidadão defender o valor da vida humana em um país que - no dia de hoje, 2 de fevereiro de 2021, soma mais de 217 mil mortos pela pandemia e que, de acordo com pesquisa de Instituto de pesquisa sediado na Austrália, fomos considerados o pior país do mundo no enfrentamento à pandemia da COVID-19. ${ }^{21}$ Essa constatação é um dado da realidade que devemos ter em mente - quando trabalhamos nesse campo - enquanto profissionais que atuam na pesquisa e no ensino.

A segunda conclusão é um registro histórico de como a inserção dos direitos humanos no ensino superior já tinha lugar no Brasil antes do surgimento da área de concentração dedicada ao tema na FDUSP. O que gostaríamos de deixar registrado é como a parceria institucional entre nossas duas unidades de origem propiciaram um exercício de troca de conhecimento.

Bibiana é professora de Direitos Humanos na $\mathrm{EACH}$, e sua experiência como docente se dá principalmente no curso de Gerontologia, campo de estudos interdisciplinares voltados ao envelhecimento humano e à velhice. Como área de

\footnotetext{
18 Idem, ibidem, p. 90-91.

19 Idem, ibidem, p. 91-98.

20 Ibidem, p. 102.

21 Disponível em: https:/www.dw.com/pt-br/brasil-fez-a-pior-gest\%C3\%A3o-do-mundo-na-pandemia-dizestudo/a-56369231. Acesso em: 3 fev. 2021.
} 
formação no ensino superior, a Gerontologia surge primeiramente no Brasil no âmbito da Pós-Graduação, ${ }^{22}$ onde ainda se situam a maioria das formações propostas em nível superior, seja no Brasil, seja em outros países. Na graduação, o primeiro Curso de Bacharelado em Gerontologia foi o da EACH/USP, iniciado em 2005, ${ }^{23}$ e a disciplina de direitos humanos foi ministrada, pela primeira vez em 2011, depois de uma reforma do Projeto Político Pedagógico do Curso, por meio da qual se buscou reforçar o chamado eixo social de estruturação dessa formação. ${ }^{24}$

Guilherme é professor do DFD e mais do que uma aprofundada reflexão teórica a respeito de interdisciplinaridade, tem um conhecimento empírico de uma década de experiência de dar aulas de graduação na Cidade Universitária.

O locus privilegiado dessa construção de conhecimento mais do que a elaboração de nossa disciplina é nossa presença na sala de aula e fora dela. Uma vez, Bibiana contou a Guilherme que Lupicínio Rodrigues foi porteiro na Faculdade de Direito da UFRGS, e que ela gostaria de ter estudado nessa época, consciente de que a Universidade não é apenas uma instituição de ensino formal, mas também de educação informal, e não-formal, no sentido Freireano. ${ }^{25}$ Vocalista, letrista e compositora em algumas formações de música eletrônica, Bibiana tem procurado trabalhar temas de direitos humanos e envelhecimento e divulgar resultados de pesquisa através de outros meios de comunicação de conhecimento e de sensibilização além das publicações bibliográficas, como a música e o teatro. $\mathrm{Na} \mathrm{EACH}$, em diversas ocasiões ministrou a disciplina optativa "Envelhecimento e velhice no cinema", e um dos frutos do projeto de pesquisa relacionada aos bairros do Brás e da Mooca foram esquetes teatrais sobre situações relatadas pelos participantes do estudo encenadas por atores e atrizes participantes da oficina de teatro do projeto de extensão USP $60+$, oficina ministrada pelo servidor da EACH e professor de teatro Rogério Pimenta. Exemplos concretos do

22 Para um panorama da constituição da Gerontologia no Brasil ver: LOPES, A. Os desafios da gerontologia no Brasil. 2. ed. Campinas: Alínea, 2010.

23 Em universidades públicas brasileiras, o Curso de bacharelado hoje também é oferecido na Universidade Federal de São Carlos (UFSCAR).

${ }^{24} \mathrm{O}$ atual Projeto Político Pedagógico do Curso pode ser consultado em: http://www5.each.usp.br/wpcontent/uploads/2020/11/PPP-GER-2020.pdf. Acesso em: 2 fev. 2021.

25 Como ensina Paulo Freire: "É uma pena que o caráter socializante da escola, o que há de informal na experiência que se vive nela, de formação ou deformação, seja negligenciado. Fala-se quase exclusivamente do ensino dos conteúdos, ensino lamentavelmente quase sempre entendido como transferência do saber. Creio que uma das razões que explicam este descaso em torno do que ocorre no espaço-tempo da escola, que não seja a atividade ensinante, vem sendo uma compreensão estreita do que é educação e do que é aprender. [...]Se estivesse claro para nós que foi aprendendo que percebemos ser possível ensinar, teríamos entendido com facilidade a importância das experiências informais nas ruas, nas praças, no trabalho, nas salas de aula das escolas, nos pátios dos recreios em que variados gestos de alunos, de pessoal administrativo, de pessoal docente se cruzam cheios de significação". FREIRE, Paulo. Pedagogia da autonomia: saberes necessários a prática educativa. 25. ed. São Paulo: Paz e Terra, 2002, p. 19-20. 
aproveitamento dessas habilidades, sensibilidades e conhecimentos artísticos em nossa disciplina foram a sugestão da leitura em francês (com tradução em português) do libelo acusatório de Zola J'accuse quando discutimos o caso Dreyfus em sala de aula, ou ainda a organização, em 2017, do cine-debate sobre o filme "A destruição de Bernardet" (2016), em presença de diretores e do próprio Jean-Claude Bernardet, no auditório da Defensoria Pública do Estado de São Paulo, o que foi viabilizado também graças ao apoio do Defensor Público Davi Quintanilha Falide de Azevedo, hoje egresso do PPGD, e que naquela época estava cursando nossa matéria.

A busca constante por novos e heterodoxos referenciais teóricos de Guilherme leva ao encontro de um pequenino e estupendo livro de Marielle Macé. ${ }^{26}$ Assim, também incorporamos em nossa abordagem a literatura, chamada a contribuir na construção do conhecimento jurídico, bem ao espírito de François Ost, em sua mais recente obra, um livro de contos:

Não é mais a grande literatura que fala do Direito, e os juristas que a comentam (direito $n a$ literatura), são juristas que pegam a caneta, contam o Direito e se interrogam sobre sua natureza, suas funções, seus valores. A literatura como via do Direito, o Direito narrado. ${ }^{27}$

Tais transferências e construções conjuntas de conhecimento entre duas trajetórias diversas e assemelhadas só se tornam possíveis no terreno do exercício constante do diálogo, procurando-se compreender a lógica de cada colega e as potencialidades da contribuição de cada singularidade para o sucesso do curso.

Encerrando essa breve reflexão a propósito da transferência de conhecimento interinstitucional, trazemos a afirmação de Axel Honneth quando propõe uma revisão do conceito de socialismo e assevera que:

(...) a nossa sociedade só se tornará social no pleno sentido da palavra quando todos os seus membros puderem satisfazer as necessidades partilhadas de intimidade física e emocional, de independência econômica e de autodeterminação política com todos os outros de tal modo que possam confiar na participação e ajuda dos seus próprios parceiros de interação. ${ }^{28}$

26 MACÉ, Marielle. Siderar, considerar: migrantes, formas de vida. Rio de Janeiro: Bazar do Tempo: 2018

27 Tradução nossa. No original: "Ce n'est pas la littérature qui parle du droit, et les juristes qui la commentent (droit dans la littérature), ce sont des juristes qui prennent la plume, racontent le droit et s'interrogent sur sa nature, ses fonctions, ses valeurs. La littérature comme voie du droit, le droit mis en récit”. OST, F. Si le droit m'était conté. Paris: Dalloz, 2019, p. 11. Nessa linha, vale mencionar o excelente livro de crônicas da juíza e escritora Andréa Pachá, uma verdadeira aula de direitos da pessoa idosa: PACHÁ, Andréa. Velhos são os outros. Rio de Janeiro: Intrínseca, 2018.

28 HONNETH, Axel. A ideia de socialismo - Tentativa de atualização. Lisboa: Edições 70, 2017, p. 148. 
PARTE II - História dos Direitos Humanos e a questão do sujeito: Uma aventura interdisciplinar

Em 21 de dezembro de 2016, foi ativada, sob nossa responsabilidade, junto ao Programa de Pós-Graduação em Direito, a disciplina formalmente denominada "História dos Direitos Humanos e o Processo de Especificação do Sujeito de Direito". ${ }^{29}$ Desde o primeiro semestre de 2017, a disciplina foi ofertada todos os anos (4 turmas), beneficiando ao total 93 estudantes, tanto do próprio programa, como também de outros programas, a exemplo do Programa de Pós-Graduação em Gerontologia, do Programa de Pós-Graduação em Psicologia Social. O interesse e a participação de estudantes graduados ou mestres em diversas áreas do conhecimento (Direito, História, Psicologia, Biologia, Enfermagem, entre outras) somados à condução conjunta de docentes com percursos acadêmicos distintos, favoreceram a configuração de um fértil ambiente de debates e trocas em matéria de direitos humanos. Essa participação diversificada permite que as interações ocorram de forma a reforçar e ampliar as potencialidades interdisciplinares que contribuem para uma compreensão menos dogmática a respeito da genealogia dos Direitos Humanos e da questão do sujeito de direito, o que se buscou igualmente imprimir no programa e na bibliografia pensados para a disciplina (1). As reflexões que vêm se consolidando a partir dessa experiência, com fundamento em diversas análises sobre a evolução histórica dos direitos humanos e as conquistas e fragilidades quanto à ampliação e ao reconhecimento do sujeito de direito, nos conduzem ao entendimento de que, no atual cenário de crise sanitária, ambiental, mas sobretudo ética e moral, ${ }^{30}$ é preciso uma refundação dos direitos humanos (2).

1) Pensando uma disciplina e duas trajetórias acadêmicas

Depois de definirmos o programa de nossa disciplina, o próximo passo é pensarmos na organização da nossa atuação como professores. O que fica estabelecido é uma divisão na apresentação dos textos em sala de aula, cabendo a cada um de nós dois a apresentação do texto e, ao outro, comentar o que está sendo apresentado. Isso cria a possibilidade de outras pessoas em sala de aula também se sentirem estimuladas a participar.

A primeira metade do programa é consagrada ao tema da genealogia histórica dos direitos humanos. Apresentamos e discutimos textos de autores das duas

29 Disciplina DHU5017-1, posteriormente sendo reativada sob o código DHU5017-2.

30 Ao nos referirmos ao aspecto moral, trata-se aqui da necessidade de se resgatar uma moralidade inclusiva em face do raso, perigoso e excludente moralismo ao qual determinadas tendências, sobretudo políticas ou religiosas, têm tentado acorrentar os direitos humanos. 
tendências para a nova historiografia dos direitos humanos descritas por Hoffmann: ${ }^{31}$ aquela que busca pontos estabilizadores para o presente, encontrando-os na longa evolução dos direitos humanos (deep history), manifestada em livro de Lynn Hunt; ${ }^{32}$ e a que procura mostrar, de forma revisionista, a instabilidade das narrativas universalistas e, portanto o caráter transitório de nossas convicções políticas e morais (história recente), assumida em obra de Samuel Moyn. ${ }^{33}$ Enquanto a autora entende que os direitos humanos ganharam espaço e auto-evidência no século XVIII, Moyn, "em contraste, defende que só se pode falar de DH como direitos individuais reconhecidos a toda pessoa, mesmo para além do estado nação, a partir dos anos 1970" (tradução nossa). ${ }^{34}$ Já para Hoffmann, os direitos humanos individuais só viriam a se tornar uma doxa, um conceito inconteste e "insubstituível" das políticas globais, apenas na década de 1990, após a Guerra Fria. ${ }^{35}$

A segunda metade do programa é dedicada para o sujeito de direito em direitos humanos. Em cada semestre, escolhemos algumas ilustrações de sujeito de direito reconhecido em suas especificidades (o que vem se manifestando igualmente na ótica do direito privado ${ }^{36}$ ). Como já mencionamos, nosso ponto de partida teórico, é a proposta de Norberto Bobbio acerca da especificação do sujeito de direito, que seria "nova linha de tendência" em matéria de direitos humanos, ao lado dos processos de "conversão em direito positivo, de generalização e de internacionalização". ${ }^{37}$ Tal elaboração é apresentada no terceiro ensaio da coletânea e que dá o título ao livro "A Era dos Direitos", tratando-se originalmente de um discurso pronunciado, em 1987, com outro título, na Universidade de Madri. Referindo-se a este escrito, o autor explica:

Ponho particularmente em evidência, pela primeira vez, como ocorreu a ampliação do âmbito dos direitos do homem na passagem do homem abstrato ao homem concreto, através de um processo de gradativa diferenciação ou especificação dos carecimentos e dos interesses, dos quais se solicita o reconhecimento e a proteção. ${ }^{38}$

Nesse diapasão, propomo-nos a estudar, por exemplo, a situação da mulher, a situação da pessoa idosa, a pessoa em situação de rua ou ainda a pessoa em situação de refúgio. Não por acaso, observamos a necessidade frequente de recurso ao

\footnotetext{
HOFFMANN, S. L. Human rights and history. Past and present, n. 232 (Aug. 2016).

HUNT, L. A invenção dos direitos humanos. Uma história. São Paulo: Companhia das Letras, 2009.

33 MOYN, S. The Last Utopia: Human rights in history. Cambridge: Belknap Press of Harvard University Press, 2010.

34 HOFFMANN, S. L., op. cit., p. 2.

35 Idem, p. 3.

36 MARQUES, Claudia Lima; MIRAGEM, Bruno. O novo direito privado e a proteção dos vulneráveis. São Paulo: RT, 2012.

37 BOBBIO, N. op. cit., p. 31.

38 BOBBIO, N., op. cit., p. 7-8.
} 
termo situação, o que, a partir dos debates e trocas empreendidos ao longo das diversas edições de nossa disciplina, foi chamando-nos a atenção para a ideia de que os sujeitos de direito reconhecidos em suas especificidades apresentam um caráter situacional, seja no tempo, seja no espaço. Como diria Simone de Beauvoir, "ninguém nasce mulher: torna-se mulher". ${ }^{39}$ Leva-se em conta, desse modo, as construções socioculturais que também influenciam e são determinantes para a caracterização e concepção dos grupos sociais. A dimensão situacional pode se referir tanto ao ciclo de vida (por exemplo, ser criança, ser velho), ou a determinando contexto (por exemplo, estar em situação de rua, ou em situação de refúgio), como também às questões identitárias e culturais, que apresentam, intrinsecamente, um caráter contingencial, evolutivo. No entanto, todas essas situações têm em comum o que faz com que, precisamente, sejam levadas em conta no processo de especificação do sujeito de direito em direitos humanos: são situações a exigir reconhecimento, inclusão; casos em que o sujeito, por conta de determinada situação, pelo seu pertencimento a determinado grupo, ou como alguns autores preferem em relação a certos grupos, em função de determinadas vulnerabilidades, enfrentam variadas formas de violência e discriminação.

Para favorecer a construção de conhecimento empírico, realizamos em edições da disciplina pré-pandemia de COVID-19 visitas em equipamentos ou serviços de acolhimento de alguns dos sujeitos de direito estudados. Foi o caso das visitas realizadas à Casa de Acolhida Morada São João, um centro de acolhida especial para pessoas idosas em situação de rua, equipamento da Secretaria Municipal de Desenvolvimento e Assistência Social do Município de São Paulo, e ao Centro de Referência para Refugiados.

É nessa parte do programa que adotamos certa flexibilidade na escolha, a cada semestre, dos grupos de sujeito de direito que serão estudados, procurando levar em consideração os interesses relacionados aos projetos de pesquisa de cada diferente turma. É também nessa parte final da disciplina que propomos que estudantes apresentem proposta de redação de um artigo científico a ser desenvolvido individualmente, em dupla ou em pequeno grupo. Estimulamos o trabalho coletivo, e abrimos a possibilidade para que a produção apresentada possa ser bibliográfica ou artística. Desses trabalhos ou projetos de artigos, alguns avançaram em uma colaboração ulterior, resultando em publicações. ${ }^{40}$

BEAUVOIR, S. O segundo sexo. 2. ed. São Paulo: Difusão Europeia do Livro, 1967, v. 2, p. 9.

40 Ver nesse sentido, a produção de um dos estudantes da primeira edição da disciplina, Maxime Péron, doutorando francês em dupla titulação entre o PPGDIR e a Faculdade de Direito da Université de Bretagne Occidentale, sob orientação da Profa. Bibiana Graeff e da Profa. Dorothée Guérin, que resultou em artigo em coautoria conosco e com a orientanda francesa: ALMEIDA, G. A.; PERON, M. ; GUERIN, D. ; GRAEFF, B. L'enfant sujet des droits de l'homme: réflexions en Droit français et en Droit brésilien. RECHTD, v. 11, 2019, p. 221-238. A disciplina também aproximou estudantes possibilitando publicações conjuntas, como : MOURA, M.-L.; PÉRON, M. Le changement de sexe en droit: approche comparatiste entre la France et le Brésil. RJO 2018, n. 2, p. 19. 
Nessa última parte de nosso artigo, apresentaremos qual é, para nós, o desafio que se apresenta para os direitos humanos diante da catástrofe climática, na esfera global, e de um presidente negacionista e genocida, na esfera doméstica.

2) Direitos humanos no antropoceno: por uma refundação

A conscientização da comunhão de destinos terrestres entre a natureza viva e a aventura humana deve tornar-se um acontecimento importante de nosso tempo: devemos nos sentir solidários com este planeta, pois nossa vida está ligada à sua existência, precisamos não só arrumá-lo, mas também poupá-lo: precisamos reconhecer nossa filiação biológica e nossa filiação ontológica; é o cordão umbilical que precisa ser reatado.

Vivemos um paradoxo: quanto mais indispensável, mais difícil é a transformação. Isso significa que ela exige perseverança e coragem. ${ }^{41}$

$\mathrm{Na}$ sabedoria dos seus cem anos de existência, Morin resume em três palavras o que nós - enquanto humanidade-devemos buscar: solidariedade, perseverança e coragem.

Podemos teorizar a propósito de solidariedade, produzir filmes ("A solidariedade é vermelha”, de Krzystof Kieslowski), todavia - no atual momento planetário - devemos praticar a solidariedade entre colegas, com estudantes, funcionários e com os que mais estão sofrendo na atual pandemia. A empiria solidária haverá de nos indicar um caminho de ação para proteção da pessoa humana em tempos sombrios. $\mathrm{O}$ que devemos lembrar é - que por mais difícil que possa parecer - devemos cuidar de nossa comunidade em todos os níveis.

A perseverança em relação à proteção dos direitos humanos deve ser dirigida à forma possível em termos jurídicos e políticos daquilo que Bruno Latour chama de "ecologia política", capaz de englobar atores humanos e não humanos. ${ }^{42}$

A prática do experimentalismo histórico em momento algum da história de nossas vidas foi tão imprescindível. Como afirma Hannah Arendt, é o princípio da natalidade que nos caracteriza como humanos. Nesse sentido, a coragem como virtude cardeal indica um caminho de refundação dos direitos humanos, capaz de superar seu atual déficit de solidariedade por se concentrar na mera definição de categorias situacionais para sujeitos específicos. Deve-se buscar formas holísticas de promoção - agora - de uma dignidade planetária englobando todes, no mais amplo sentido possível e imaginável.

MORIN, E. É hora de mudarmos de via: lições do coronavírus. Rio de Janeiro: Bertrand Brasil, 2020 p. 84.

42 LATOUR, B. Políticas da natureza: Como associar ciências à democracia São Paulo: Editora UNESP, 2019, p.105-106. 